\title{
Enhancement of gold catalytic activity and stability by immobilization on the surface of graphene
}

\author{
David Ventura-Espinosa, ${ }^{\mathrm{a}}$ Sara Sabater ${ }^{\mathrm{a}}$ and Jose A. Mata ${ }^{* a}$ \\ a Institute of Advanced Materials (INAM), Universitat Jaume I, Avda. Sos Baynat s/n, 12006, \\ Castellón (Spain). Fax: (+34) 964387522; Tel: (+34) 964387516; e-mail: jmata@uji.es
}

\begin{abstract}
The catalytic performance of gold complexes is evaluated at the molecular level and when supported onto reduced graphene oxide (rGO). Gold complexes of general formula $[(\mathrm{NHC}) \mathrm{AuX}]$ catalyse the synthesis of indoles via intramolecular hydroamination reaction of alkynes. The catalytic properties of the molecular gold complexes are highly improved when supported onto graphene. Faster reaction rates and higher catalyst stability are observed for the immobilized gold complexes. The use of graphene as support of molecular complexes has a positive benefit in the catalytic gold properties in terms of activity and stability
\end{abstract}

\section{Introduction}

The use of gold as catalyst has acquired a great impact over the last years. [1-3] Although initially considered as an inert noble metal, gold has proved his potential application in catalysis. [4] The gold catalytic activity is very high in the form of solid catalysts, [5-7] nanoparticles, [8-11] clusters,[12] or molecular complexes.[13-19] Despite the advances of gold in homogeneous catalysis, one of the main drawbacks that still needs to be tackled is stability. In particular, stability of gold complexes towards decomposition under common catalytic conditions. Stability issues of gold complexes should address to a rational design of more active and robust catalysts that inhibit regular decomposition pathways.[20-23] At the molecular level, decomposition of gold complexes comes from the nature and number of intermediates involved in a catalytic cycle and its inherent facile reduction to form inactive gold metallic mirrors. In order to improve catalytic efficiency and activity it is important to develop systems in which deactivation or reduction pathways are minimised or avoided. An alternative to circumvent this problem consists of the immobilization 
of organometallic complexes onto solid surfaces capable of enhancing their stability.[24-28] Immobilization of molecular complexes combines the advantages of homogeneous and heterogeneous catalysis of selectivity and robustness.[29-32] Catalytic applications of welldefined molecular complexes onto supports are widened as they can be recovered and reused for several catalytic cycles. In addition, separation of the solid catalyst from reaction products is crucial for many applications. The use of solid supports for immobilization of molecular complexes allows the controlled incorporation of catalytic active sites. Structural characterization of the active sites facilitates the understanding of structure-reactivity relationships that govern the catalytic performance and stability.

In this work, we aim to study different factors that may play a role over the control of stability of gold complexes during catalytic reactions. In this context, we have developed a methodology that allows the immobilization of well-defined gold complexes onto the surface of graphene. The structure of the hybrid material is composed of a regular distribution of active sites completely characterized. Here, we show that the rationale ligand design and immobilization of organometallic complexes on the surface of graphene enhance the gold catalytic properties.

\section{Results and Discussion}

The gold/graphene hybrid materials were prepared using a general procedure previously described in our laboratory that allows the controlled introduction of molecular complexes onto the surface of graphene.[33] The method consists in the direct immobilization of gold complexes onto the surface of reduced graphene oxide (rGO) by $\pi$-stacking interactions.[34-36] These type of interactions are important in the case of polyaromatic hydrocarbons (PAHs) including graphene and related materials.[37] We have used a pyrene tag for the preparation of two imidazolium salts that serve as NHC ligand precursors and allow the direct immobilization of the organometallic gold complexes onto the surface of graphene (Scheme 1). The imidazolium salts 1 and 2 containing the pyrene tag were prepared in good yields by alkylation of methyl (or mesityl) imidazole with 1-bromomethylpyrene. Deprotonation of the imidazolium salts using a transmetalation procedure or an external base in the presence of $\mathrm{AuCl}\left(\mathrm{SMe}_{2}\right)$ allows the formation of the well-defined organometallic gold complexes $\mathbf{3}$ and $\mathbf{4}$. The gold complexes were fully characterized by NMR spectroscopy, ESI-MS spectrometry and elemental analysis. The ESI-MS analysis requires the addition of an external sodium or potassium salt to detect the molecular peak. For instance, in the case of complex 3 , the base peak corresponds to an adduct with potassium at $567.03 \mathrm{~m} / \mathrm{z}$. The mass/charge relation and the isotopic pattern confirm the molecular composition. Single crystal X-ray diffraction completes the characterization of 3 and 4 (Figures 1 and 2). The Au- $\mathrm{C}_{\text {carbene }}$ distance is 1.974(4) $\AA$ for 3 and 2.000(3) $\AA$ for $\mathbf{4}$ and both lye in the expected range for gold NHC 
complexes. The packing diagram of complex 3 shows an intermolecular $\pi$-stacking interaction between the pyrene groups (Figure 1). The interplanar distance is $3.5 \AA$, indicating an interaction between the polyaromatic groups. The same situation is observed in the case of the gold complex 4. The packing diagram shows a $\pi$-stacking interaction between the pyrene groups with an interplanar distance of $3.6 \AA$ (Figure 2 ). We have previously observed the formation of $\pi-\pi$ interactions in palladium[33] and ruthenium[38] NHC complexes functionalized with pyrene tags. The formation of these $\pi-\pi$ interactions gives an indication of the tendency of the pyrene tag to interact with PAHs such as graphene.
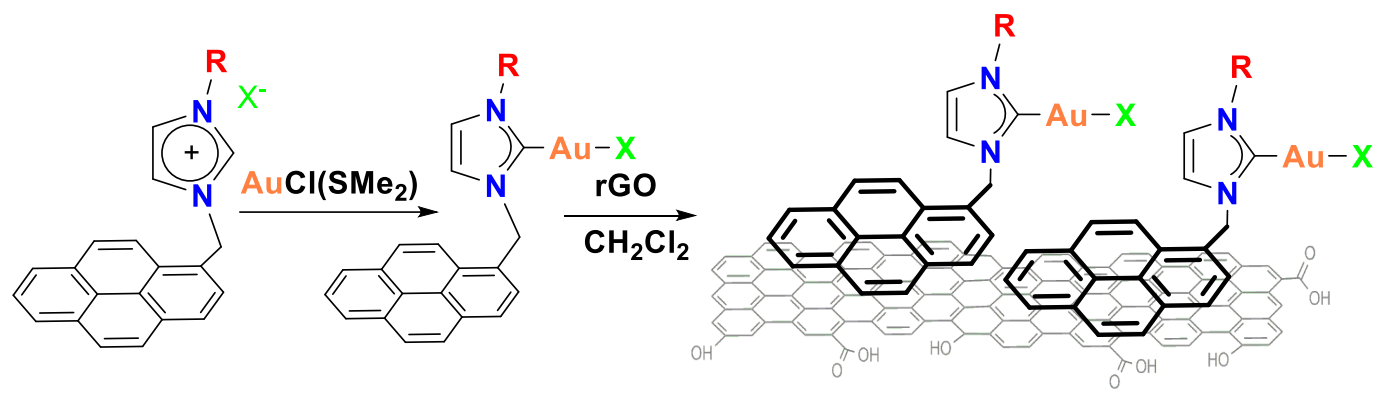
$1, \mathrm{R}=\mathrm{Me}$
3, $\mathrm{R}=\mathrm{Me}, \mathrm{X}=\mathrm{Cl}$
5, $\mathrm{R}=\mathrm{Me}, \mathrm{X}=\mathrm{Cl}$
2, $R=$ Mes
4, $\mathrm{R}=$ Mes, $\mathrm{X}=\mathrm{Br}$
6, $R=$ Mes, $X=B r$

Scheme 1. Synthesis of gold complexes and hybrid materials.

Gold complexes $\mathbf{3}$ and $\mathbf{4}$ are immobilized on rGO at room temperature using ultrasounds (US). The exact amount of gold complex anchored on the surface of graphene was analysed by ICP-MS. The results accounted for a $3.9 \mathrm{wt} \%$ of complex 3 in the hybrid material 5 and $0.9 \mathrm{wt} \%$ of complex 4 in the hybrid material 6. The hybrid materials were characterized by UV/Vis, FTIR and HRTEM. Analysis by X-ray photoelectron spectroscopy (XPS) provides evidence of the structure of the molecular complexes on the surface of graphene. Figure 3 shows a comparative XPS analysis of the molecular complex 4 and the hybrid material 6. Complex 4 shows three characteristic peaks corresponding to the core-levels of N1s, Au4f and Br3d. These peaks are also observed in the XPS of the hybrid material 6 at the same binding energy. XPS analysis confirms the presence of the molecular complex 4 on the surface of the reduced graphene oxide and that the structure of complex $\mathbf{4}$ is maintain after immobilization.

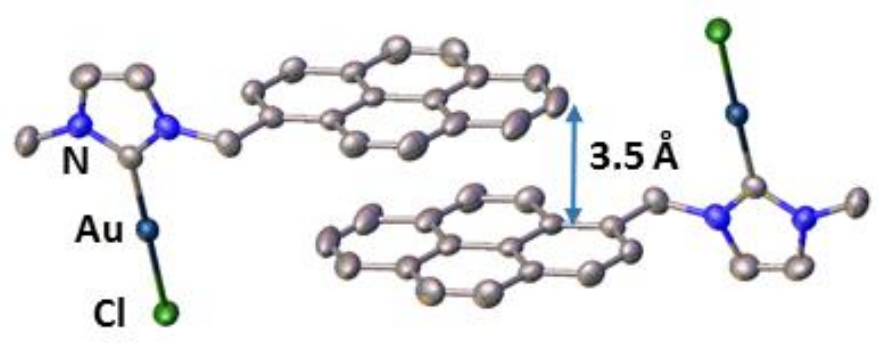


Figure 1. Crystal packing diagram of compound 3. Ellipsoids are at 50\% probability level. Hydrogen atoms have been omitted for clarity. The $\pi$-stacking interplanar distance between the pyrene-tags is $3.5 \AA$.

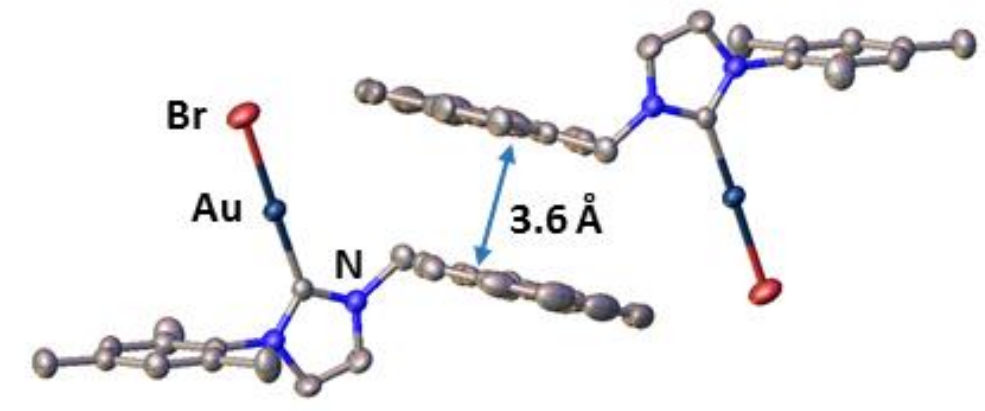

Figure 2. Crystal packing diagram of compound 4. Ellipsoids are at 50\% probability level. Hydrogen atoms have been omitted for clarity. The $\pi$-stacking interplanar distance between the pyrene-tags is $3.6 \AA$.
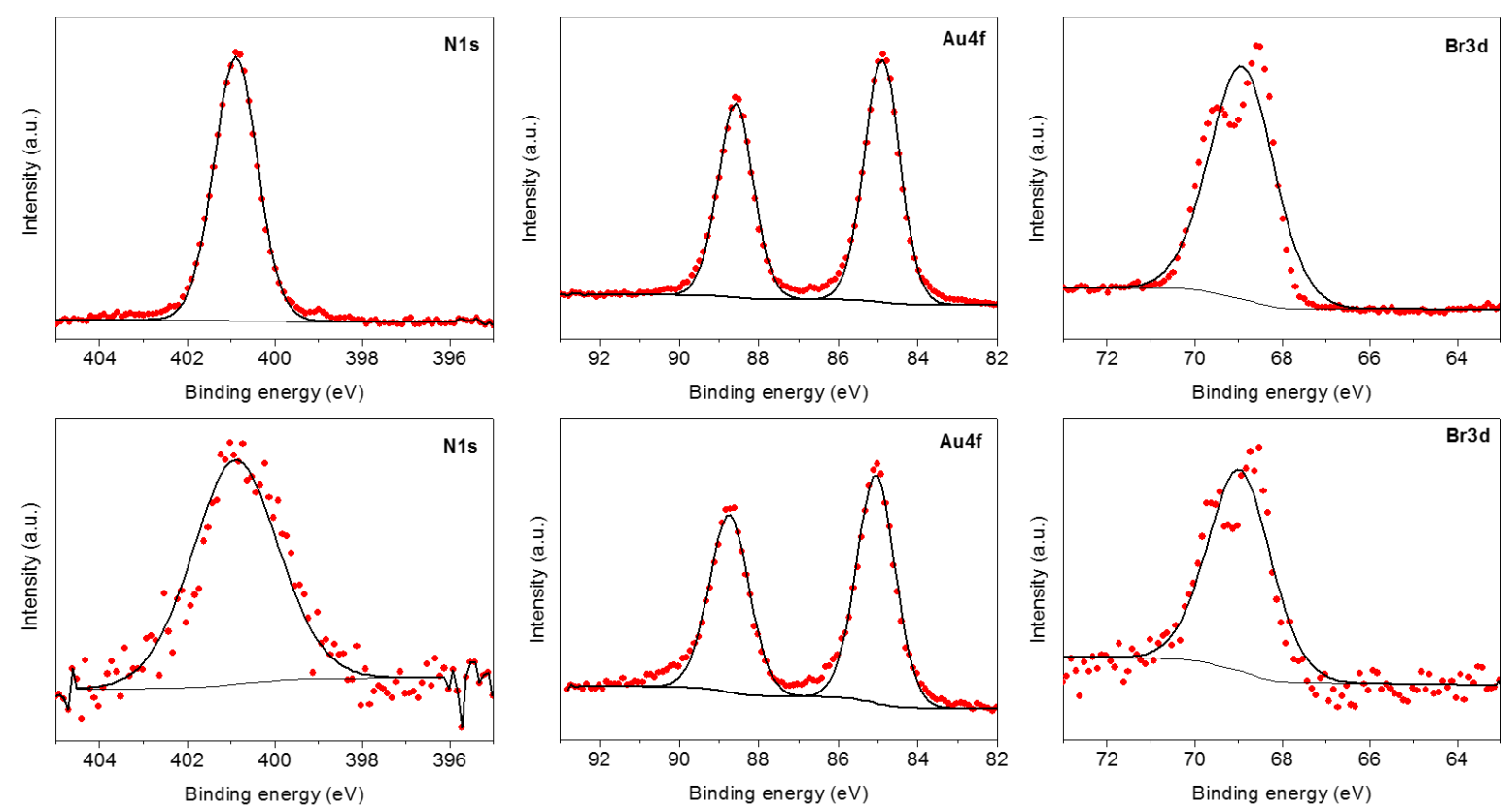

Figure 3. Comparative XPS analysis of molecular complex 4 (top) and hybrid material 6 (down) for the core-level peaks of N1s, Au4f and Br3d.

\section{Catalytic properties}

We tested the catalytic properties of the molecular gold complexes and the hybrid materials using the intramolecular hydroamination of alkynes as model reaction.[39-42] The catalytic formation of indole derivatives is an elegant approach for the synthesis of sophisticated organic molecules. The reaction mechanism is well stablished and requires the addition of $\mathrm{AgBF}_{4}$ to activate the gold 
precatalyst. The gold catalysts $(3-\mathbf{6})$ are active in the cyclisation reactions (Table 1) at low temperatures. Initial control experiments show that $\mathrm{Au}$ is required in the reaction to proceed, $\mathrm{AgBF}_{4}$ or rGO material are not active. (Data not shown table 1, see SI for details). Results show that the catalytic performance of $\mathbf{3}-\mathbf{6}$ is particularly different. For instance, the performance of catalyst 3 is very low, only $20 \%$ yield is obtained after $6 \mathrm{~h}$ reaction (Entry 1). However, under the same reaction conditions, 4 and $\mathbf{5}$ afforded $91 \%$ and $82 \%$ yield respectively (Entries 3 and 8). We observed that the overall turnover was even better in the case of catalyst $\mathbf{6}$, which afforded quantitative yields in $1.5 \mathrm{~h}$ with a catalyst loading of $0.08 \mathrm{~mol} \%$ (Entry 9). These results are remarkably considering that standard conditions on gold-catalysed intramolecular hydroamination of alkynes require catalyst loadings in the range of $1-2$ mol\%.[43-46] The reaction affords quantitative yields when using acetonitrile or toluene as solvents, but only $15 \%$ yield is obtained when using thf (Entry 6). We have not observed differences on mass balances in the presence of the support when monitoring the reactions by gas chromatography. This result suggests that the $\pi$ stacking interactions of substrates with the support are weak and therefore they are not adsorbed. The use of catalyst 6 allows the reduction of reaction time to minutes at a low catalyst loading of $0.56 \mathrm{~mol} \%$ (Entry 10). These results show that better outcomes are obtained when using catalyst 6 in toluene at low temperature.

A hot filtration experiment was carried out to stablish the heterogeneous nature of catalyst 6 during the intramolecular hydroamination. We performed the experiment under the reaction conditions described in entry 9 (Table 1), but after $45 \mathrm{~min}$. (GC yield 53\%), the catalytic hybrid material 6 was separated from the solution by cannula-filtration at the working temperature (50 $\left.{ }^{\circ} \mathrm{C}\right)$. The filtrate was stirred under the same conditions for $5 \mathrm{~h}$ at $50^{\circ} \mathrm{C}$. After this time, GC analysis reveals that there is no more indole formation. This result suggests that there are not catalytic active species in solution. On the other hand, the isolated catalyst $\mathbf{6}$ was treated with toluene and substrate. After $2 \mathrm{~h}$ reaction, we observed the formation of indole in $97 \%$ yield. The results suggest the heterogeneous nature of catalyst 6 . The hot filtration experiment confirmed the absence of leached species in solution due to desorption from the graphene surface. 
Table 1. Optimization parameters for the intramolecular hydroamination of alkynes.

\begin{tabular}{|c|c|c|c|c|c|c|}
\hline Entry & Cat. & {$[\mathrm{Au}](\mathrm{mol} \%)$} & $\mathrm{R}$ & Solv. & $\mathrm{t}(\mathrm{h})$ & Yield $(\%)^{\mathrm{a}}$ \\
\hline 1 & 3 & 1 & $\mathrm{Ph}$ & Toluene & 6 & 20 \\
\hline 2 & 4 & 1 & $\mathrm{nBu}$ & “6 & 24 & 71 \\
\hline 3 & 4 & 1 & $\mathrm{Ph}$ & “ & 6 & 91 \\
\hline 4 & 4 & 2 & $\mathrm{Ph}$ & “6 & 1 & 100 \\
\hline $5^{\mathrm{b}}$ & 4 & 2 & $\mathrm{Ph}$ & “ & 1 & 100 \\
\hline 6 & 4 & 2 & $\mathrm{Ph}$ & $\mathrm{THF}$ & 6 & 15 \\
\hline 7 & 4 & 2 & $\mathrm{Ph}$ & $\mathrm{MeCN}$ & 1 & 100 \\
\hline 8 & 5 & 1 & $\mathrm{Ph}$ & Toluene & 6 & 82 \\
\hline $9^{c}$ & 6 & 0.08 & $\mathrm{Ph}$ & Toluene & 1.5 & 100 \\
\hline 10 & 6 & 0.56 & $\mathrm{Ph}$ & Toluene & 0.2 & 100 \\
\hline
\end{tabular}

a) Reactions carried out at a substrate concentration of $0.0625 \mathrm{M}$. Yields determined by GC analysis using anisole as the internal standard. Three equivalents of $\mathrm{AgBF}_{4}$ respect to gold catalyst. b) Reaction carried out under $\mathrm{N}_{2}$ atmosphere. c) A hot filtration experiment was carried out under these conditions.

The catalytic performance evaluation of $\mathbf{3}-\mathbf{6}$ was compared by monitoring the cyclization reaction during time (Figure 4). The catalytic rate of the molecular gold complexes $\mathbf{3}$ and $\mathbf{4}$ is remarkably different (Figure 4a). Under the same reactions conditions and catalyst loading, complex $\mathbf{3}$ affords only $20 \%$ yield but complex 4 affords $100 \%$ yield. As observed in the monitoring of the reaction, catalyst 3 is completely deactivated after $300 \mathrm{~min}$. The results show that the introduction of an aromatic ring at the nitrogen positon of the NHC ligand affords a higher stability and catalyst performance. This situation is also observed in the case of the supported catalysts $\mathbf{5}$ and $\mathbf{6}$ (Figure 4b). Catalyst 6, with a mesityl group, affords quantitative yield after $100 \mathrm{~min}$. at a catalyst loading of only $0.1 \mathrm{~mol} \%$. In the case of catalyst $\mathbf{5}$, the reaction stops after $400 \mathrm{~min}$. reaching an $80 \%$ yield but using a ten-fold catalyst loading. These results show that catalyst stability increases by ligand design. Introduction of aromatic rings at the nitrogen positons of the NHC ligand increases catalyst stability and activity. More interesting is the effect observed when the molecular gold complexes 
$\mathbf{3}$ and $\mathbf{4}$ are anchored on rGO. The reaction rates in the case of $\mathbf{3}$ are slow, indicating a limited catalytic performance (Figure 4c). For instance, the yield after $400 \mathrm{~min}$. is only 19\%. After this time, the reaction practically stops and there is no more indole formation. The molecular complex is completely deactivated suggesting a limited catalyst stability. When the molecular complex $\mathbf{3}$ is supported onto graphene forming the hybrid material $\mathbf{5}$, the catalytic properties are improved. The hybrid material 5 affords $85 \%$ yield instead of $19 \%$ after $400 \mathrm{~min}$. Immobilization of the molecular complex $\mathbf{3}$ on the surface of graphene has a positive effect in terms of reaction rates (activity) and product formation (Figure 4c). This effect is even more pronounced in the case of the molecular complex 4 and its corresponding hybrid material 6 (Figure 4d). In the case of catalyst $\mathbf{6}$, quantitative yield is obtained in $12 \mathrm{~min}$. but only $80 \%$ is obtained after $600 \mathrm{~min}$ when using the molecular catalyst 4 . The reaction profile for $\mathbf{4}$ and $\mathbf{6}$ shows a huge difference in catalyst performance. Most often, reaction rates are negatively affected by immobilization of the molecular complexes due to diffusion problems. This is especially important when using porous supports. In our case, we have observed the reversed situation. The reaction rates increase after immobilization of the molecular complexes on the surface of graphene, indicating that there are not diffusion problems. Although at this point, we do not have a plausible explanation for the increase of reaction rates, the process is general, and it has been observed for other catalytic systems using graphene.[47,48] Immobilization onto reduced graphene oxide has a positive effect on the catalytic properties of gold molecular complexes by increasing stability and activity.
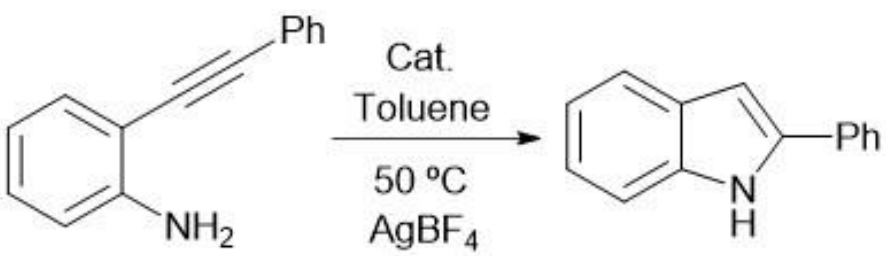

a)

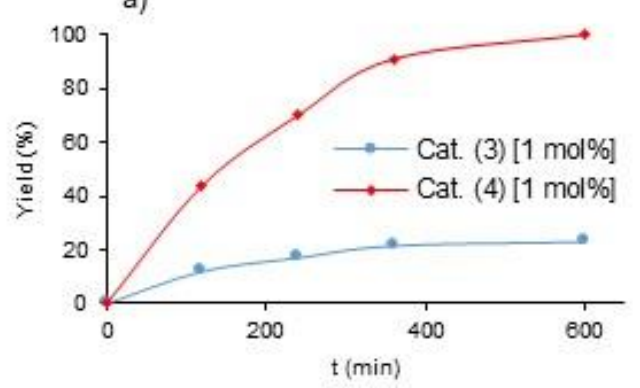

c)

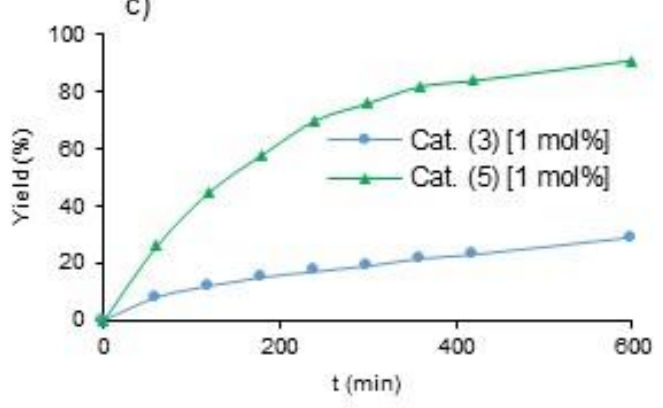

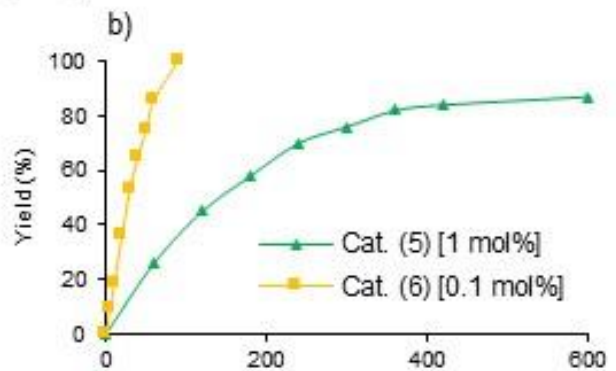

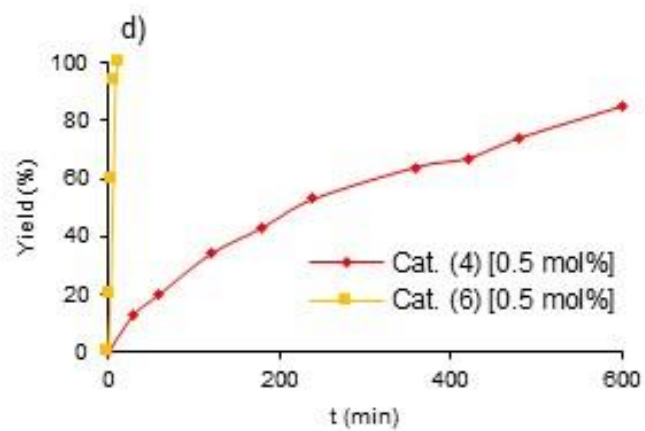


Figure 4. Reaction monitoring of the intramolecular hydroamination of alkynes using different catalysts.

\section{Recycling studies}

The stability of the hybrid catalyst (6) was further analysed by recyclability studies. Recycling experiments were carried out using the standard conditions described in Figure 5 at a $0.5 \mathrm{~mol} \%$ catalyst loading. The reaction was monitored by gas chromatography (GC) using anisole as internal standard. After each run, the mixture was allowed to reach room temperature and the solid catalyst was separated by decantation, washed with toluene and used in the next run (Figure 5). The results show that the hybrid catalyst 6 was reused without any significant loss of activity for four consecutive runs. In runs 5 and 6, the catalytic performance decreases and longer reaction times are required to achieve quantitative yields. In order to evaluate the deactivation pathways, the gold content in the solution was analysed by ICP-MS after each run. The results show that the gold content in the solution corresponding to runs 1 to 3 is negligible (less than $2 \mathrm{wt} \%$ ). In contrast, the gold content after run 6 corresponds to a $50 \mathrm{wt} \%$ loss of the initial gold content of the material. These results suggest that deactivation of the hybrid material $\mathbf{6}$ is caused by both, leaching and complex degradation. Despite the low amount of gold content after six runs, the molecular complex anchored in the surface of graphene is stable enough to achieve quantitative yields.
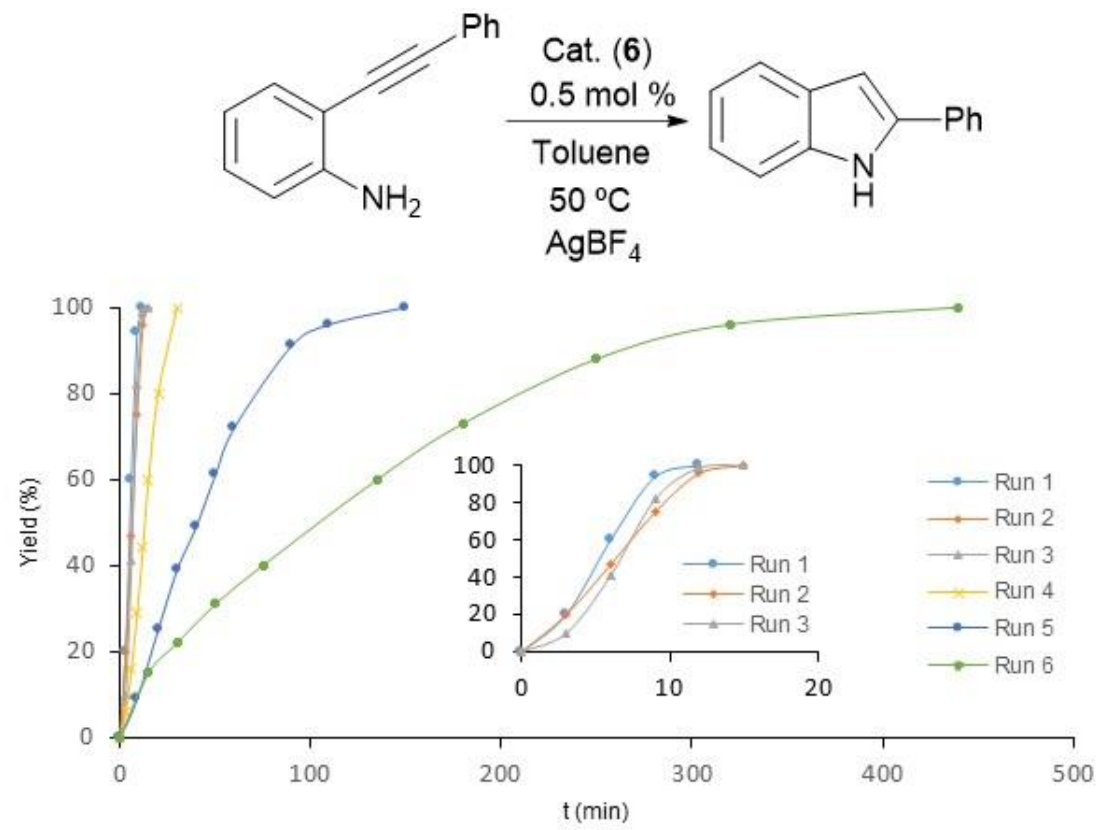

Figure 5. Recycling experiments on the intramolecular hydroamination reaction using the hybrid material catalyst (6). Reaction profile for each run determined by GC analysis. 
The catalytic hybrid material 6 was further analysed by HRTEM after the recycling experiments. Microscopy evaluation allows exploring any possible changes in the graphene morphology and/or the possibility of gold nanoparticles formation (Figure 6). A comparison of the HRTEM images of catalyst 6 before and after the recycling experiments shows the same morphology for the graphene hybrid material. The only difference is the presence of more wrinkles, because of the mechanical stirring during the catalytic reactions. There are not gold metal nanoparticles and the single layer of graphene is maintained.
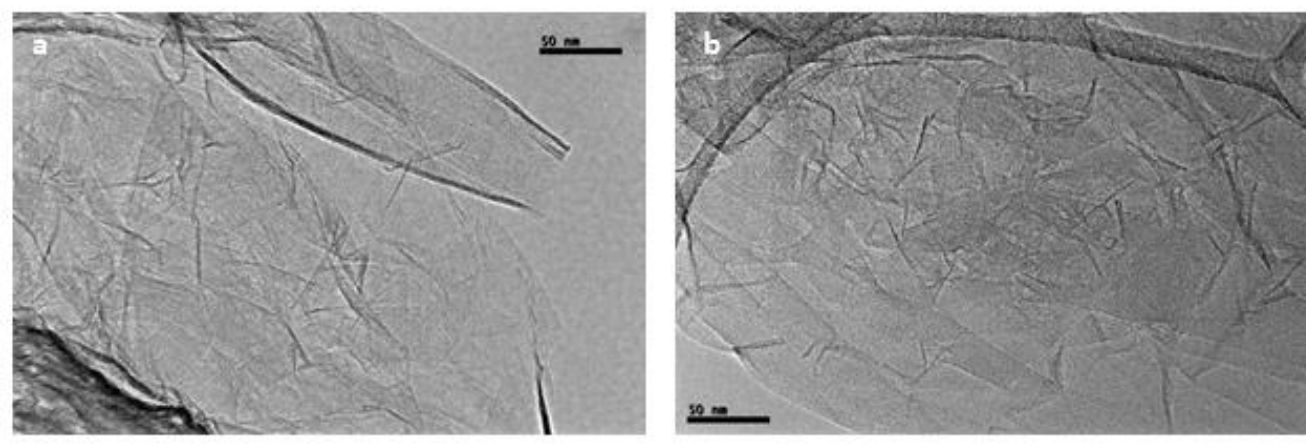

Figure 6. HRTEM images of $\mathbf{6}$ before (a) and after (b) six catalytic runs.

\section{Conclusions}

In this manuscript, we have explored the factors that favour the catalytic performance and stability of gold complexes anchored on the surface of graphene. Gold complexes containing an Nheterocyclic carbene ligand functionalized with a pyrene group are straightforward immobilized on the surface of reduced graphene oxide by $\pi-\pi$ interactions. This methodology grants the immobilization of well-defined gold molecular complexes onto a graphene surface and allows the direct comparison in activity of the molecular and the supported gold complexes. The gold complexes and the corresponding hybrid materials are active catalysts in the intramolecular hydroamination of alkynes. At the molecular level, ligand modification increases rates and stability by introducing an aromatic ring at the nitrogen positon of the NHC ligand. We have observed that the catalytic performance is improved in the hybrid materials compared to the molecular complexes. Normally, immobilization of molecular complexes onto supports have a negative effect in activity due to diffusion problems. The hybrid catalytic materials based on graphene show higher reaction rates than the corresponding molecular complexes. The results suggest that there are not diffusion problems when using graphene as support. In addition to catalyst performance, we have observed that the hybrid materials are active during more time affording quantitative 
yields. The use of graphene as support enhance the catalyst stability most probably by inhibiting decomposition pathways. We have shown that immobilization of molecular gold complexes on the surface of graphene improves catalytic performance and stability. Future research to establish the role of graphene is ongoing in our laboratory.

\section{Experimental Section}

Experimental Details. Anhydrous solvents were dried using a solvent purification system (SPS M BRAUN). The imidazolium salt $\mathbf{1}$ and the substrates used for catalysis were obtained according to reported procedures.[33,49] Nuclear magnetic resonance (NMR) spectra were recorded on Bruker spectrometers operating at 300 or $400 \mathrm{MHz}\left({ }^{1} \mathrm{H} \mathrm{NMR}\right)$ and 75 or $100 \mathrm{MHz}\left({ }^{13} \mathrm{C}\left\{{ }^{1} \mathrm{H}\right\} \mathrm{NMR}\right)$, respectively, and referenced to $\mathrm{SiMe}_{4}$ ( $\delta$ in ppm and $\mathrm{J}$ in Hertz). NMR spectra were recorded at room temperature with the appropriate deuterated solvent. High-resolution images of transmission electron microscopy HRTEM and high-angle annular dark-field HAADF-STEM images of the samples were obtained using a Jem-2100 LaB6 (JEOL) transmission electron microscope coupled with an INCA Energy TEM 200 (Oxford) energy dispersive X-Ray spectrometer (EDX) operating at $200 \mathrm{kV}$. Samples were prepared by drying a droplet of a $\mathrm{MeOH}$ dispersion on a carbon-coated copper grid. X-ray photoelectron spectra (XPS) were acquired on a Kratos AXIS ultra DLD spectrometer with a monochromatic Al Ka X-ray source $(1486.6 \mathrm{eV})$ using a pass energy of 20 $\mathrm{eV}$. To provide a precise energy calibration, the XPS binding energies were referenced to the $\mathrm{C} 1 \mathrm{~s}$ peak at $284.6 \mathrm{eV}$.

Synthesis of 2. To a solution of 1-(Bromomethyl)pyrene (750 mg, $2.75 \mathrm{mmol})$ in dry THF (8 mL) was added 1-mesityl imidazole $(0.465 \mathrm{mg}, 2.5 \mathrm{mmol})$. The mixture was refluxed under nitrogen for $16 \mathrm{~h}$. The resulting suspension was filtered off and washed with diethyl ether $(2 \times 10 \mathrm{~mL})$. The imidazolium salt was obtained as a white solid. Yield: $1.1 \mathrm{~g}(90 \%) .{ }^{1} \mathrm{H}$ NMR (400 MHz, $\left.\mathrm{CD}_{3} \mathrm{OD}\right)$ $\delta 9.36(\mathrm{~s}, 1 \mathrm{H}, \mathrm{NCHN}), 8.48-7.97\left(\mathrm{~m}, 9 \mathrm{H}, \mathrm{CH}_{\mathrm{pyr}}\right), 7.89$ (s, 1H, $\left.\mathrm{CH}_{\text {imid }}\right), 7.69$ (s, $\left.1 \mathrm{H}, \mathrm{CH}_{\text {imid }}\right), 7.06$ (s, 2H, CH $H_{\text {mes }}$ ), 6.34 (s, 2H, $\left.\mathrm{CH}_{2, \text { pyr }}\right), 2.32$ (s, 3H, CH3, mes), $2.00\left(\mathrm{~s}, 6 \mathrm{H}, \mathrm{CH}_{3}\right.$, mes). ${ }^{13} \mathrm{C}\left\{{ }^{1} \mathrm{H}\right\} \mathrm{NMR}$ $\left(101 \mathrm{MHz}, \mathrm{CD}_{3} \mathrm{OD}\right) \delta 142.5(\mathrm{NCHN}),[138.8,135.7,133.9,132.6,131.9,130.6,130.5,129.7$, $129.4,128.3,127.7,127.3,127.1,126.9,126.4,126.2,125.8,125.5,124.6,122.5]\left(C_{\mathrm{pyr}}, C \mathrm{H}_{\mathrm{imid}}\right.$, $\left.C_{\text {mes }}\right) 52.8\left(\mathrm{~N}-\mathrm{CH}_{2}\right), 21.1\left(\mathrm{CH}_{3, \text { mes }}\right), 17.3\left(\mathrm{CH}_{3, \text { mes }}\right)$. Anal. Calcd. for $\mathrm{C}_{29} \mathrm{H}_{25} \mathrm{~N}_{2} \mathrm{Br}: \mathrm{C}, 72.34 ; \mathrm{H}, 5.23$; N, 5.81. Found: C, 71.89; H, 5.51; N, 6.09. Electrospray MS (Cone 20 V) (m/z, fragment): 401.3 $[\mathrm{M}]^{+}$.

Synthesis of 3. In a round-bottom flask were mixed, under exclusion of light, the imidazolium salt 1 (128.3 mg, $0.339 \mathrm{mmol})$ and $\mathrm{Ag}_{2} \mathrm{O}(78 \mathrm{mg}, 0.339 \mathrm{mmol})$ in $10 \mathrm{~mL}$ of acetonitrile. The suspension was heated at reflux during 5 hours. After cooling, $\left[\mathrm{AuCl}\left(\mathrm{SMe}_{2}\right)\right](100 \mathrm{mg}, 0,339 \mathrm{mmol})$ and $\mathrm{KCl}$ (243 $\mathrm{mg}, 3,25 \mathrm{mmol}$ ) were added and the reaction mixture was stirred at room temperature for 15 
hours. The insolubles were filtered off through a pad of kieselguhr. The filtrate was concentrated under reduced pressure yielding a white precipitate. Recrystallization using dichloromethane/hexane afforded an analytically pure white solid. Yield: $145 \mathrm{mg}(81 \%)$. ${ }^{1} \mathrm{H}$ NMR $\left(300 \mathrm{MHz}, \mathrm{CDCl}_{3}\right) \delta 8.20-7.91\left(\mathrm{~m}, 8 \mathrm{H}, \mathrm{CH}_{\mathrm{pyr}}\right), 7.79\left(\mathrm{~d}, J=7.8 \mathrm{~Hz}, 1 \mathrm{H}, \mathrm{CH}_{\mathrm{pyr}}\right), 6.71(\mathrm{~d}, J=1.9$ $\left.\mathrm{Hz}, 1 \mathrm{H}, \mathrm{CH}_{\text {imid }}\right), 6.54\left(\mathrm{~d}, J=1.9 \mathrm{~Hz}, 1 \mathrm{H}, \mathrm{CH}_{\text {imid }}\right), 5.84\left(\mathrm{~s}, 2 \mathrm{H}, \mathrm{CH}_{2}\right), 3.78\left(\mathrm{~s}, 3 \mathrm{H}, \mathrm{NCH}_{3}\right) .{ }^{13} \mathrm{C} \mathrm{NMR}$ $\left(75 \mathrm{MHz}, \mathrm{CDCl}_{3}\right): \delta 171.3\left(C_{\text {carbene- }} \mathrm{Au}\right),[131.8,131.0,130.4,128.9,128.1,127.5,127.1,126.9$, 126.3, 125.8, 125.7, 124.8, 124.3] $\left(C_{\mathrm{Pyr}}, \mathrm{CH}_{\mathrm{imid}}\right), 52.9\left(\mathrm{CH}_{2}\right), 38.3\left(\mathrm{NCH}_{3}\right)$. Anal. Calcd. for $\mathrm{C}_{21} \mathrm{H}_{16} \mathrm{~N}_{2} \mathrm{AuCl}$ (528.78 g/mol): C, 47.70; H, 3.05; N, 5.30. Found: C, 47.87; H, 3.27; N, 5.39. Electrospray MS. (Cone 20V) (m/z, fragment): $567.2[\mathrm{M}+\mathrm{K}]^{+}$. HRMS ESI-TOF-MS (positive mode): $[\mathrm{M}+\mathrm{K}]^{+}$monoisotopic peak 567.0309; calc. 567.0305, $\varepsilon_{\mathrm{r}}: 0.7 \mathrm{ppm}$.

Synthesis of 4. In a pyrex tube, imidazolium salt (2) (100 mg, $0.2 \mathrm{mmol})$, [AuCl( $\left.\mathrm{SMe}_{2}\right)$ ] (60.7 mg (0.206 mmol), $\mathrm{K}_{2} \mathrm{CO}_{3}(28.5 \mathrm{mg}, 0.206 \mathrm{mmol})$ and $2.4 \mathrm{~mL}$ of acetone were heated at $60{ }^{\circ} \mathrm{C}$ for 3 hours. Then, the solvent was removed under vacuum, dichloromethane was added $(10 \mathrm{~mL})$ and the mixture was filtered through silica. The pad of silica was washed with dichloromethane (10 $\mathrm{mL}$ ). The solvent was reduced to approximately $2 \mathrm{~mL}$ and pentane was added, affording a white solid, which was filtered and dried in vacuum. Yield: $90 \mathrm{mg}(66 \%) .{ }^{1} \mathrm{H} \mathrm{NMR}\left(300 \mathrm{MHz}, \mathrm{CDCl}_{3}\right)$ $\delta 8.35\left(\mathrm{~d}, J=9.2 \mathrm{~Hz}, 1 \mathrm{H}, \mathrm{C} H_{\mathrm{pyr}}\right), 8.30-7.98\left(\mathrm{~m}, 8 \mathrm{H}, \mathrm{C} H_{\mathrm{pyr}}\right), 6.97\left(\mathrm{~s}, 2 \mathrm{H}, \mathrm{C} H_{\mathrm{mes}}\right), 6.80$ (d, $J=2.0$ $\left.\mathrm{Hz}, 1 \mathrm{H}, \mathrm{CH} H_{\text {imid }}\right), 6.73$ (d, J=2.0 Hz, 1H, CH $\mathrm{imid}_{\text {) }}, 2.34$ (s, 3H, $\mathrm{CH}_{3, \mathrm{mes}}$ ), 2.06 (s, $\left.6 \mathrm{H}, \mathrm{CH}_{3, \mathrm{mes}}\right) .{ }^{13} \mathrm{C}$ NMR (75 MHz, $\left.\mathrm{CDCl}_{3}\right) \delta 176.10$ ( $\left.C_{\text {carbene- }} \mathrm{Au}\right),[139.88,134.92,134.80,132.37,131.33,130.74$, 129.61, 129.52, 129.23, 128.53, 128.02, 127.38, 127.30, 126.60, 126.16, 126.11, 125.35, 125.06, 124.65, 122.52, 122.31, 120.25] ( $\left.C_{\text {Pyr }}, C H_{\text {imid }}, C_{\text {mes }}\right), 53.67\left(\mathrm{~N}-C_{2}\right), 21.27\left(\mathrm{CH}_{3, \text { mes }}\right), 18.00$ $\left(\mathrm{CH}_{3, \mathrm{mes}}\right)$. Anal. Calcd for $\mathrm{C}_{29} \mathrm{H}_{24} \mathrm{~N}_{2} \mathrm{AuBr} \cdot 0.5 \mathrm{C}_{5} \mathrm{H}_{12}$ : C, 52.98; H, 4.20; N, 3.92. Found: C, 53.27; $\mathrm{H}, 3.76$; N, 4.15. The calculated elemental analysis fits with the experimental with the addition of half a molecule of n-pentane that is also observed in the ${ }^{1} \mathrm{H}$ NMR of complex 4 (Section S3.3). Electrospray MS (Cone $20 \mathrm{~V})(\mathrm{m} / \mathrm{z} \text {, fragment): } 763.03 \text { [M-Br+I+K }]^{+}$. HRMS ESI-TOF-MS (positive mode): [M-Br+I+K] $]^{+}$monoisotopic peak 763.0305; calc. 763.0287, $\varepsilon_{\mathrm{r}}: 2.4$ ppm.

Synthesis of 5 and 6. A suspension of $90 \mathrm{mg}$ of $\mathrm{rGO}$ in $10 \mathrm{~mL}$ of $\mathrm{CH}_{2} \mathrm{Cl}_{2}$ was inmersed in an ultrasounds bath for $30 \mathrm{~min}$. Then, $10 \mathrm{mg}$ of $\mathbf{3}$ or $\mathbf{4}$ was added to the mixture. The suspension was stirred at room temperature for 10 hours. The black solid was isolated by filtration and washed with $2 \times 15 \mathrm{~mL}$ of $\mathrm{CH}_{2} \mathrm{Cl}_{2}$ affording the hybrid material as a black solid. The exact amount of supported complex was determined by ICP-MS analysis. The results accounted for a $3.9 \mathrm{wt} \%$ of complex 3 in the hybrid material 5 and 0.9 wt\% of complex 4 in the hybrid material 6. The hybrid materials were characterized by UV/Vis, FTIR and HRTEM (See Supporting Information for details). 
General procedure for the catalytic experiments. Catalytic experiments were performed under air in a pyrex tube, using $0.3 \mathrm{mmol}$ of substrate, $2.4 \mathrm{~mL}$ of solvent, catalyst $(0.1-2.0 \mathrm{~mol} \%)$ and $\mathrm{AgBF}_{4}(6 \mathrm{~mol} \%)$, and heating at $50^{\circ} \mathrm{C}$. Yields and conversions were determined by GC analysis using anisole as internal standard. Isolated yields were determined by ${ }^{1} \mathrm{H}$ NMR spectroscopy using 1,3,5-trimethoxybenzene as the external standard.

\section{Acknowledgements}

The authors thank the financial support from MINECO (CTQ2015-69153-C2-2-R), Generalitat Valenciana (AICO/2015/039) and Universitat Jaume I (P1.1B2015-09). D. V-E thanks MINECO for a FPU grant (FPU15/03011). The authors are very grateful to the 'Serveis Centrals d'Instrumentació Cientifica (SCIC)' of the Universitat Jaume I. We thank S. Solans for XPS analysis.

\section{Appendix A. Supplementary material}

Electronic Supplementary Information available: Experimental details, characterization of molecular complexes and materials, XPS details, crystallographic data, HRTEM images. CCDC $1548664(3)$ and 1548665 (4).

\section{References}

[1] A.S.K. Hashmi, G.J. Hutchings, Angew. Chem. Int. Ed. 45 (2006) 7896-7936.

[2] G.C. Bond, D.T. Thompson, Catal. Rev. Sci. Eng. 41 (1999) 319-388.

[3] D.J. Gorin, F.D. Toste, Nature 446 (2007) 395-403.

[4] A.S.K. Hashmi, Chem. Rev. 107 (2007) 3180-3211.

[5] A. Corma, P. Serna, Science 313 (2006) 332-334.

[6] A. Arcadi, Chem. Rev. 108 (2008) 3266-3325.

[7] M.-C. Daniel, D. Astruc, Chem. Rev. 104 (2004) 293-346.

[8] A. Corma, H. Garcia, Chem. Soc. Rev. 37 (2008) 2096-2126.

[9] A. Primo, A. Corma, H. García, Phys. Chem. Chem. Phys. 13 (2011) 886-910.

[10] M. Haruta, Chem. Rec. 3 (2003) 75-87.

[11] M. Haruta, Catal. Today 36 (1997) 153-166.

[12] J. Oliver-Meseguer, J.R. Cabrero-Antonino, I. Dominguez, A. Leyva-Perez, A. Corma, Science 
338 (2012) 1452-1455.

[13] E. Jiménez-Núñez, A.M. Echavarren, Chem. Rev. 108 (2008) 3326-3350.

[14] A.S.K. Hashmi, Angew. Chem. Int. Ed. 49 (2010) 5232-5241.

[15] A. Fürstner, P.W. Davies, Angew. Chem. Int. Ed. 46 (2007) 3410-3449.

[16] D. Canseco-Gonzalez, A. Petronilho, H. Mueller-Bunz, K. Ohmatsu, T. Ooi, M. Albrecht, J. Am. Chem. Soc. 135 (2013) 13193-13203.

[17] N. Marion, S.P. Nolan, Chem. Soc. Rev. 37 (2008) 1776-1782.

[18] A. Collado, A. Gómez-Suárez, Y. Oonishi, A.M.Z. Slawin, S.P. Nolan, Chem. Commun. 49 (2013) 10745-10747.

[19] M.R. Fructos, T.R. Belderrain, P. de Frémont, N.M. Scott, S.P. Nolan, M.M. Díaz-Requejo, P.J. Pérez, Angew. Chem. Int. Ed. 44 (2005) 5284-5288.

[20] R.H. Crabtree, Chem. Rev. 115 (2015) 127-150.

[21] P.W.N.M. van Leeuwen, J.C. Chadwick, Homogeneous Catalysts, Wiley-VCH Verlag GmbH \& Co. KGaA, Weinheim, Germany, 2011.

[22] C.M. Crudden, D.P. Allen, Coord. Chem. Rev. 248 (2004) 2247-2273.

[23] L.S. Sharninghausen, J. Campos, M.G. Manas, R.H. Crabtree, Nat. Commun. 5 (2014) 1-9.

[24] K.P. De Jong, Synthesis of Solid Catalysts, Wiley-VCH Verlag GmbH \& Co. KGaA, Weinheim, Germany, 2009.

[25] C. Copéret, A. Comas-Vives, M.P. Conley, D.P. Estes, A. Fedorov, V. Mougel, H. Nagae, F. Núñez-Zarur, P.A. Zhizhko, Chem. Rev. 116 (2016) 323-421.

[26] M.P. Conley, C. Copéret, Top. Catal. 57 (2014) 843-851.

[27] P. Serna, B.C. Gates, Acc. Chem. Res. 47 (2014) 2612-2620.

[28] M. Tada, Y. Iwasawa, Coord. Chem. Rev. 251 (2007) 2702-2716.

[29] T.K. Maishal, J. Alauzun, J.-M. Basset, C. Copéret, R.J.P. Corriu, E. Jeanneau, A. Mehdi, C. Reyé, L. Veyre, C. Thieuleux, Angew. Chem. Int. Ed. 47 (2008) 8654-8656.

[30] M.P. Conley, C. Copéret, C. Thieuleux, ACS Catal. 4 (2014) 1458-1469.

[31] M.K. Samantaray, J. Alauzun, D. Gajan, S. Kavitake, A. Mehdi, L. Veyre, M. Lelli, A. Lesage, L. Emsley, C. Copéret, C. Thieuleux, J. Am. Chem. Soc. 135 (2013) 3193-3199.

[32] J.A. Gladysz, Pure Appl. Chem. 73 (2001) 1319-1324.

[33] S. Sabater, J.A. Mata, E. Peris, ACS Catal. 4 (2014) 2038-2047.

[34] M.R. Axet, O. Dechy-Cabaret, J. Durand, M. Gouygou, P. Serp, Coord. Chem. Rev. 308 (2016) 236-345. 
[35] B.F. Machado, P. Serp, Catal. Sci. Technol. 2 (2012) 54-75.

[36] R. Zhong, A.C. Lindhorst, F.J. Groche, F.E. Kühn, Chem. Rev. 117 (2017) 1970-2058.

[37] S. Sabater, J.A. Mata, in:, Non-Covalent Interact. Synth. Des. New Compd., John Wiley \& Sons, Inc, Hoboken, NJ, 2016, pp. 313-326.

[38] D. Ventura-Espinosa, C. Vicent, M. Baya, J.A. Mata, Catal. Sci. Technol. 6 (2016) 8024-8035.

[39] W. Debrouwer, T.S.A. Heugebaert, B.I. Roman, C. V. Stevens, Adv. Synth. Catal. 357 (2015) 2975-3006.

[40] R.A. Widenhoefer, X. Han, European J. Org. Chem. 2006 (2006) 4555-4563.

[41] K. Fujita, A. Fujii, J. Sato, H. Yasuda, Synlett 27 (2016) 1941-1944.

[42] J.C. Timmerman, S. Laulhé, R.A. Widenhoefer, Org. Lett. 19 (2017) 1466-1469.

[43] A. Zhdanko, M.E. Maier, Angew. Chem. Int. Ed. 53 (2014) 7760-7764.

[44] D. Kadzimirsz, D. Hildebrandt, K. Merz, G. Dyker, Chem. Commun. 49 (2006) 661-662.

[45] M. Michalska, K. Grela, Synlett 27 (2015) 599-603.

[46] C.A. Gaggioli, G. Ciancaleoni, L. Biasiolo, G. Bistoni, D. Zuccaccia, L. Belpassi, P. Belanzoni, F. Tarantelli, Chem. Commun. 51 (2015) 5990-5993.

[47] D. Ventura-Espinosa, A. Marzá-Beltrán, J.A. Mata, Chem. Eur. J. 22 (2016) 17758-17766.

[48] S. Sabater, J.A. Mata, E. Peris, Organometallics 34 (2015) 1186-1190.

[49] J.P. Brand, C. Chevalley, J. Waser, Beilstein J. Org. Chem. 7 (2011) 565-569. 
Intramolecular Hydroamination<smiles>[R]C#Cc1ccccc1N</smiles>

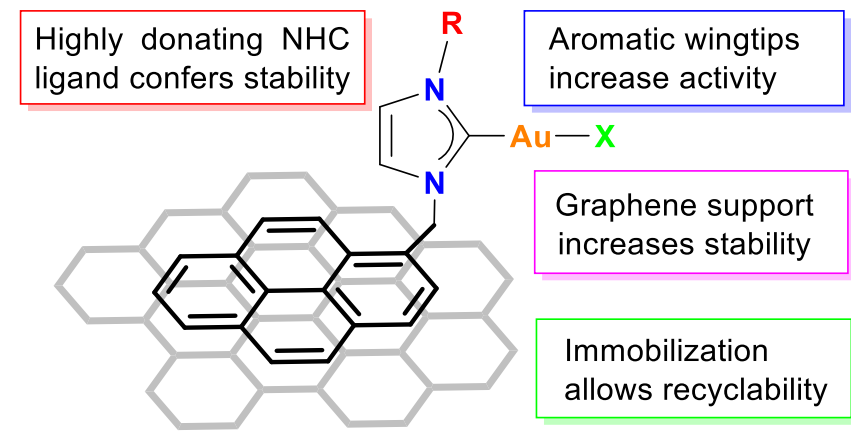

Graphene as an ideal support for molecular catalysts: Gold complexes anchored on the surface of rGO show faster reaction rates and higher stability. 